\title{
Reduction of Ochratoxin A during the Preparation of Porridge with Sodium Bicarbonate and Fructose
}

\author{
Hyun Jung Lee ${ }^{1, *(\mathbb{D})}$, Shufang $\mathrm{Li}^{2}$, Kejia Gu${ }^{3}$ and Dojin Ryu ${ }^{1, *}$ (i) \\ 1 Department of Animal, Veterinary, and Food Sciences, University of Idaho, 875 Perimeter Drive MS 2330, \\ Moscow, ID 83844-2330, USA \\ 2 Institute of Quality Standards and Testing Technology for Agro-Products, Henan Academy of Agricultural \\ Science, Zhengzhou 450002, China; lishufang@hnagri.org.cn \\ 3 School of Food Science, Washington State University, P.O. Box 646376, Pullman, WA 99164-6376, USA; \\ Kejia.gu@wsu.edu \\ * Correspondence: hlee@uidaho.edu (H.J.L.); dryu@uidaho.edu (D.R.)
}

check for updates

Citation: Lee, H.J.; Li, S.; Gu, K.; Ryu, D. Reduction of Ochratoxin A during the Preparation of Porridge with Sodium Bicarbonate and Fructose. Toxins 2021, 13, 224. https://doi.org/ $10.3390 /$ toxins 13030224

Received: 18 February 2021

Accepted: 16 March 2021

Published: 19 March 2021

Publisher's Note: MDPI stays neutral with regard to jurisdictional claims in published maps and institutional affiliations.

\begin{abstract}
Ochratoxin A (OTA) is a potential human carcinogen that poses a significant concern in food safety and public health. OTA has been found in a wide variety of agricultural commodities, including cereal grains. This study investigated the reduction of OTA during the preparation of riceand oat-based porridge by a simulated indirect steam process. The effects of sodium bicarbonate $\left(\mathrm{NaHCO}_{3}\right)$ and fructose on the reduction of OTA were also investigated. During the processing, OTA in rice- and oat-porridge was decreased by $59 \%$ and $14 \%$, respectively, from initial OTA artificially added at $20 \mu \mathrm{g} / \mathrm{kg}$ (dry weight basis). When $0.5 \%$ and $1 \%$ of sodium bicarbonate were added to rice porridge, increased reduction of OTA was observed as $78 \%$ and $68 \%$, respectively. The same amounts of added sodium bicarbonate also further reduced OTA in oat porridge to $58 \%$ and $72 \%$, respectively. In addition, increased reduction of OTA in the presence of fructose was observed. A combination of the two, i.e., $0.5 \%$ sodium bicarbonate and $0.5 \%$ fructose, resulted in a $79 \%$ and $67 \%$ reduction in rice porridge and oat porridge, respectively. These results indicate that indirect steaming may effectively reduce OTA in preparation of porridge-type products, particularly when sodium bicarbonate and/or fructose are added.
\end{abstract}

Keywords: Ochratoxin A (OTA); indirect steaming; sodium bicarbonate; fructose

Key Contribution: Indirect steaming is the most common method to produce porridges. OTA reductions were $59 \%$ in rice porridge and $14 \%$ in oat porridge, while up to $79 \%$ of OTA was reduced by adding sodium bicarbonate and fructose.

\section{Introduction}

Oats (Avena sativa) have been cultivated mainly in temperate regions worldwide as an important part of the human diet for millennia and are used in the production of various foods, including breakfast cereals, infant cereals, and snacks. Oats have been gaining popularity in recent decades due to their health benefits, such as reducing cardiovascular diseases and promoting immune functions driven by soluble fibers, including $\beta$-glucans [1-3]. Meanwhile, higher incidences and levels of ochratoxin A (OTA) have been reported from oats and oat-based products compared to other cereal grains such as wheat and corn and their products [4-8].

OTA is one of the major naturally occurring foodborne mycotoxins and is produced by a number of Aspergillus and Penicillium species. OTA is a possible human carcinogen in Group 2B with sufficient evidence of carcinogenicity in experimental animal studies $[9,10]$. In addition to its prominent nephrotoxicity, OTA is known to be hepatotoxic, teratogenic, mutagenic, and immunosuppressive [10-12]. Moreover, public health concerns are increasing worldwide as OTA frequently contaminates many commodities, including nuts, spices, dried fruits, and most cereal grains around the globe [13-16]. 
The majority of previous reports on the heat stability of OTA are in agreement that the complete reduction of OTA may not be achieved by conventional methods of food processing [17-24]. Steaming is a major food process that uses water vapor or heat, accompanied by the correct degree of temperature, and pressure as well sometimes. There are two kinds of steaming methods- "low-pressure steaming," also called indirect steaming in this manuscript, and "high-pressure steaming," such as direct steam injection (DSI) or retorting. While low-pressure steaming is a process where food is steamed through neither indirect nor direct contact with the steam, high-pressure steaming requires some equipment or containers that will not enable steam and/or heat to escape from food. Due to the major benefit of steaming that nutrients such as Vitamin C and B will not be lost from applying this method, steaming is one of the most popular food processes to make grain porridge products for the old and the infirm, who are more vulnerable to the toxic effects of OTA than healthy people. Since each liter of water at $100{ }^{\circ} \mathrm{C}$ requires approximately $2250 \mathrm{KJ}$ or 5.35 times more energy to make dry steam than it does to raise the same amount of water from $0{ }^{\circ} \mathrm{C}$ to $100{ }^{\circ} \mathrm{C}$ [25], high-pressure steaming provides very quick heat transfer and could be effective in reducing OTA in foods despite the short processing time [19,24]. Unlike high-pressure steaming, such as DSI and retorting, [19,24], the effects of low-pressure steaming, such as indirect steaming, on the reduction of OTA have not been studied so far. In this study, two distinctively different matrices, i.e., rice and oats with different compositions including fiber content, were employed to study the heat stability of OTA during a simple thermal process of indirect steaming. As a practical measure to enhance the reduction of OTA, the effects of adding sodium bicarbonate and fructose were also investigated.

\section{Results}

The color of food products is an important yet simple and fast quality indicator, as it can serve as an indicator of physicochemical properties, including the amount of pigments [26]. As shown in Table 1, the addition of sodium bicarbonate $\left(\mathrm{NaHCO}_{3}\right)$ affected the color of rice- and oat-based porridges significantly. Decreased lightness $(L)$ with added sodium bicarbonate was observed in both rice and oat porridges after the cooking process $(p<0.05)$, while the redness $(a)$ of the porridges increased significantly $(p<0.05)$. When sodium bicarbonate was added, increased yellowness $(b)$ was observed in the cooked rice porridge but no significant changes in oat porridge. With added fructose, only rice porridge showed an increasing trend in yellowness $(b)$.

The analytical method for OTA employed in this study was verified with the recovery ranged $79-92 \%$ for rice- and $104-111 \%$ for oat-based samples. In addition, the limit of detection (LOD) and limit of quantification (LOQ) for rice- and oat-based samples were $0.032 \mu \mathrm{g} / \mathrm{kg}$ and $0.10 \mu \mathrm{g} / \mathrm{kg}, 0.038 \mu \mathrm{g} / \mathrm{kg}$ and $0.12 \mu \mathrm{g} / \mathrm{kg}$, respectively. The values of LOD and LOQ were determined with their respective signal-to-noise ratio, i.e., 3 and 10.

Rice and oats were hired for the current study in an attempt to explain greater frequency and levels of OTA in oat-based products in comparison with other cereal-based processed foods $[4-7,27]$. During the cooking process at $80-85^{\circ} \mathrm{C}$ of center temperature, $59.4 \%$ and $13.6 \%$ reduction of OTA concentration was observed in rice- and oat- porridge, respectively. Moreover, the effects of sodium bicarbonate and fructose on OTA during thermal processing in a simulated indirect steaming process were demonstrated with the two different matrices of rice and oats (Table 2).

In the two food matrices, the amount of added sodium bicarbonate showed varying effects on the reduction of OTA observed (Table 2). When compared with the reduction of the toxin in rice porridge cooked with no additive $(59.4 \%)$, the addition of $0.5 \%$ and $1.0 \%$ sodium bicarbonate resulted in the reduction of $78.1 \%$ and $68.7 \%$, respectively. On the other hand, added sodium bicarbonate made a greater impact in oat porridge by increasing the reduction of OTA from $13.6 \%$ (no additive control) to $57.7 \%$ and $72.6 \%$ with $0.5 \%$ and $1.0 \%$ sodium bicarbonate, respectively. 
Table 1. Effects of indirect steaming process and adding sodium bicarbonate, fructose, or combination of them on color parameters of retorted rice-based and oat-based porridge.

\begin{tabular}{|c|c|c|c|c|c|c|}
\hline \multirow{2}{*}{ Sample } & \multicolumn{2}{|l|}{ Additives } & \multirow{2}{*}{$L^{1}$} & \multirow{2}{*}{$A^{2}$} & \multirow{2}{*}{$B^{3}$} & \multirow{2}{*}{$\Delta E^{4}$} \\
\hline & Type & $\begin{array}{l}\text { Amount } \\
(\%, w / w)^{5}\end{array}$ & & & & \\
\hline \multirow{8}{*}{$\begin{array}{l}\text { Rice-based } \\
\text { porridge }\end{array}$} & \multicolumn{2}{|l|}{ No additives } & $89.1 \pm 1.4^{\mathrm{a}, 6}$ & $-0.7 \pm 0.1^{\mathrm{a}}$ & $8.6 \pm 0.5^{c}$ & $1.9 \pm 1.6^{b}$ \\
\hline & \multirow{3}{*}{ Sodium bicarbonate } & 0.5 & $85.9 \pm 0.7^{c}$ & $-2.1 \pm 0.4^{c}$ & $15.5 \pm 1.0^{\mathrm{a}}$ & $6.4 \pm 1.7^{\mathrm{a}}$ \\
\hline & & 1 & $86.7 \pm 0.3^{b c}$ & $-3.1 \pm 0.2^{\mathrm{d}}$ & $17.2 \pm 1.7^{\mathrm{a}}$ & $8.0 \pm 1.6^{\mathrm{a}}$ \\
\hline & & 0.5 & $89.2 \pm 0.6^{\mathrm{a}}$ & $-0.8 \pm 0.1^{\mathrm{a}}$ & $8.9 \pm 0.6^{c}$ & $1.1 \pm 0.5^{\mathrm{b}}$ \\
\hline & \multirow{2}{*}{ Fructose } & 1 & $87.8 \pm 0.9^{a b c}$ & $-0.8 \pm 0.1^{\mathrm{a}}$ & $9.7 \pm 1.0^{b c}$ & $1.2 \pm 1.3^{\mathrm{b}}$ \\
\hline & & 5 & $87.1 \pm 0.5^{a b c}$ & $-0.9 \pm 0.2^{\mathrm{a}}$ & $10.8 \pm 1.1^{b c}$ & $1.9 \pm 1.3^{b}$ \\
\hline & & 10 & $88.7 \pm 0.3^{\mathrm{ab}}$ & $-0.6 \pm 0.0^{\mathrm{a}}$ & $10.6 \pm 1.0^{b c}$ & $0.9 \pm 0.5^{b}$ \\
\hline & Sodium bicarbonate + fructose & $0.5+0.5$ & $87.2 \pm 0.6^{\mathrm{abc}}$ & $-1.5 \pm 0.1^{b}$ & $12.3 \pm 1.0^{b}$ & $3.0 \pm 0.5^{b}$ \\
\hline \multirow{8}{*}{$\begin{array}{l}\text { Oat-based } \\
\text { porridge }\end{array}$} & \multicolumn{2}{|l|}{ No additives } & $72.3 \pm 3.4^{a}$ & $3.1 \pm 0.6^{\mathrm{ab}}$ & $19.6 \pm 2.3^{\mathrm{NS}}$ & $3.1 \pm 1.6^{b c}$ \\
\hline & \multirow{3}{*}{ Sodium bicarbonate } & 0.5 & $67.5 \pm 2.3^{a b}$ & $2.7 \pm 0.2^{b}$ & $18.5 \pm 0.8$ & $4.2 \pm 2.3^{b c}$ \\
\hline & & 1 & $61.5 \pm 1.3^{c}$ & $1.7 \pm 0.2^{c}$ & $19.7 \pm 0.8$ & $10.2 \pm 1.2$ \\
\hline & & 0.5 & $72.9 \pm 1.2^{\mathrm{a}}$ & $2.8 \pm 0.2^{b}$ & $18.4 \pm 0.2$ & $1.5 \pm 1.2^{\mathrm{c}}$ \\
\hline & \multirow{3}{*}{ Fructose } & 1 & $70.6 \pm 1.6^{\mathrm{ab}}$ & $3.2 \pm 0.2^{a b}$ & $18.4 \pm 0.4$ & $1.3 \pm 0.9^{c}$ \\
\hline & & 5 & $67.6 \pm 1.6^{a b}$ & $3.8 \pm 0.2^{\mathrm{a}}$ & $20.1 \pm 0.5$ & $4.2 \pm 1.8^{b c}$ \\
\hline & & 10 & $71.2 \pm 1.2^{\mathrm{a}}$ & $3.2 \pm 0.2^{\mathrm{ab}}$ & $19.0 \pm 0.2$ & $1.0 \pm 0.8^{c}$ \\
\hline & $\begin{array}{l}\text { Combination of sodium } \\
\text { bicarbonate and fructose }\end{array}$ & $0.5+0.5$ & $65.7 \pm 1.7^{b c}$ & $2.8 \pm 0.1^{b}$ & $18.1 \pm 0.1$ & $5.9 \pm 1.4^{b}$ \\
\hline
\end{tabular}

\footnotetext{
${ }^{1}$ Degree of lightness (white $+100 \rightarrow 0$ black). ${ }^{2}$ Degree of redness (red $+100 \rightarrow-80$ green). ${ }^{3}$ Degree of yellowness (yellow $+70 \rightarrow$ -80 blue). ${ }^{4}$ Total color difference $(\Delta E)=\sqrt{\left(L-L_{0}\right)^{2}+\left(a-a_{0}\right)^{2}+\left(b-b_{0}\right)^{2}}$, where, $L, a$, and $b$ are values for the product, and $L_{0}, a_{0}$ and $b_{0}$ are values for the raw composite grains. ${ }^{5}$ Additive percent amount of rice/oat flour $(w / w) .{ }^{6}$ All values are mean $\pm \mathrm{SD}$ and different superscript letters ${ }^{a, b, c, d}$ indicate significant difference between groups within same commodity at $p<0.05$ by Tukey's multiple range tests. $\mathrm{NS}$ means not significant.
}

Table 2. Effects of added sodium bicarbonate and fructose on the reduction of ochratoxin A (OTA) in rice-based and oat-based porridges.

\begin{tabular}{|c|c|c|c|}
\hline \multicolumn{2}{|l|}{ Additives } & \multicolumn{2}{|c|}{ OTA Reduction (\%) ${ }^{1}$} \\
\hline Type & Amount $(\%, w / w)^{2}$ & Rice-Based Porridge & Oat-Based Porridge \\
\hline \multicolumn{2}{|l|}{ No additives } & $59.4 \pm 1.9^{\mathrm{c}, 3}$ & $13.6 \pm 1.2^{\mathrm{e}, *}$ \\
\hline \multirow{3}{*}{ Sodium bicarbonate } & 0.5 & $78.1 \pm 1.8^{\mathrm{a}}$ & $57.7 \pm 6.5^{\mathrm{bc}, *}$ \\
\hline & 1 & $68.7 \pm 0.5^{b}$ & $72.6 \pm 2.0^{\mathrm{a}}$ \\
\hline & 0.5 & $62.5 \pm 1.2 \mathrm{bc}$ & $47.3 \pm 4.3^{\mathrm{cd}, *}$ \\
\hline \multirow{3}{*}{ Combination of sodium bicarbonate and fructoce } & 1 & $80.7 \pm 3.1^{\mathrm{a}}$ & $69.3 \pm 5.0^{\mathrm{ab}, *}$ \\
\hline & 5 & $66.1 \pm 1.2^{b c}$ & $47.5 \pm 7.8^{\mathrm{cd}, *}$ \\
\hline & 10 & $60.0 \pm 5.3^{c}$ & $40.7 \pm 1.2^{\mathrm{d}, *}$ \\
\hline Combination of sodium bicarbonate and fructose & $0.5+0.5$ & $78.6 \pm 1.0^{\mathrm{a}}$ & $67.2 \pm 5.9 \mathrm{ab}$ \\
\hline
\end{tabular}

${ }^{1}$ OTA reduction $(\%)=(1$ - OTA concentration in retorted sample/OTA concentration in unsteamed sample $) \times 100$; moisture adjusted

${ }^{2}$ Additive percent amount of rice/oat flour $(w / w) .{ }^{3}$ All values are mean $\pm \mathrm{SD}$ and different superscript letters ${ }^{\mathrm{a}, \mathrm{b}, \mathrm{c}, \mathrm{d}, \mathrm{e}}$ indicate significant difference between groups within same commodity at $p<0.05$ by Tukey's multiple range tests and star symbols * indicate significant difference between same treatment groups at $p<0.05$ by independent samples $t$-test.

The addition of fructose also resulted in a significant reduction of OTA in both matrices depending on the amount (Table 2). When fructose was added at $0 \%, 0.5 \%, 1 \%, 5 \%$, and $10 \%(w / w)$ in this study, observed OTA reductions in rice porridge were $59.4 \%, 62.5 \%$, $80.7 \%, 66.1 \%$, and $60.0 \%$, respectively, while the reductions in oat porridge were more evident with $13.6 \%, 47.3 \%, 69.3 \%, 47.5 \%$, and $40.7 \%$, respectively. It may be noted that adding fructose at $1 \%$ resulted in the highest reduction of OTA in both food matrices then gradually decreased with the increasing amount of added fructose. Although observed reduction was greater in rice porridge, i.e., $80.7 \%$ reduction at the peak, actual impact or benefit of adding fructose seemed greater in oat porridge as 55.7\% more OTA was reduced with $1 \%$ fructose in comparison with the no sugar added control, i.e., from $13.6 \%$ to $69.3 \%$. 


\section{Discussion}

It is well known that OTA is very heat stable compared with other mycotoxins, while significant reduction of OTA may be observed under alkaline conditions or high temperature with high pressure, such as extrusion $[17,19,21,28,29]$. In order to increase $\mathrm{pH}$ or achieve alkaline conditions in food, using sodium bicarbonate or baking soda would be the only feasible option as it is generally recognized as safe or GRAS [30]. In the case of sugar as an additive, its effect on the reduction of toxicity of OTA during food processing has not been studied, while adding sugars reduced the amount and toxicity of other mycotoxins, such as fumonisin $B_{1}$ during extrusion [31,32]. Even though the chemical structures of fumonisin $B_{1}$ and OTA are different, we investigated the possibility using three different sugars of glucose, fructose, and sucrose and observed increased reduction of OTA during thermal processing by adding fructose [33]. According to the study [33], adding fructose resulted in a significantly lower OTA level than glucose, sucrose, or no-sugaradded samples. At the side of toxicity, moreover, the addition of fructose resulted in an increased OTA degradation products profile to less toxic OT $\alpha$-amide, not only significantly reduced the OTA level [33]. Contrastively, an increased OTA isomer level, which has similar toxicity to OTA, was produced by adding glucose, sucrose, or no sugar [33]. Previously, Lee $\mathrm{Gu}$, Ganjyal, and Ryu [19] reported a $19.8 \%$ and $27.9 \%$ reduction of OTA in oat slurry during a DSI process operated at $85^{\circ} \mathrm{C}$ and $121^{\circ} \mathrm{C}$, respectively. Other studies also suggested the role of matrices on the reduction of OTA at varying extents. Ryu, Kowalski, Ganjyal, and Lee [21] demonstrated that OTA reduction in rice flour ranged $77.9-82.2 \%$ while the toxin in oat flake was reduced by $39.5-42.7 \%$ during the same processing conditions of a laboratoryscale twin-screw extruder. During autoclaving of oatmeal and rice cereal for up to $3 \mathrm{~h}$, the reduction of OTA ranged from $86.0 \%$ to $87.5 \%$ while the extent of reduction was decreased to $74.0 \%$ and $68.5 \%$ when the samples were autoclaved with $50 \%(v / w)$ water [34]. Another simple food processing method of explosive puffing under varying pressures ranging from 0.5 to $0.9 \mathrm{MPa}$ resulted in greater reduction of OTA in oats (37.7-52.2\%) in comparison with the reduction in rice (15.3-28.4\%) [20].

Meanwhile, specific heat may help understanding the matrix effect as it equals to the sum of pondered contribution of each component including carbohydrates, protein, lipids, salts, and water. While the specific heat of water is $4.18 \mathrm{~kJ} / \mathrm{kg}$ or $1 \mathrm{cal} / \mathrm{g}$, the specific heat of the major components is taken as: salts $=0.2$; carbohydrate $=0.34$; protein $=0.37$; and lipids $=0.4$ relative to water [35]. According to USDA FoodData Central [36], oat flour $(100 \mathrm{~g})$ contains $13.33 \mathrm{~g}$ of protein; $6.67 \mathrm{~g}$ of lipids; $73.33 \mathrm{~g}$ of carbohydrate, while rice flour $(100 \mathrm{~g})$ contains $3.57 \mathrm{~g}$ of protein; $0.89 \mathrm{~g}$ of lipids; $80.36 \mathrm{~g}$ of carbohydrate. Since specific heat is different by component of food matrix, its heat transfer or heat energy can affect OTA differently in different matrices.

The amount of added sodium bicarbonate showed varying effects on the reduction of OTA in the two food matrices (rice and oat) observed (Table 2). It may be noted that the increased amounts of added sodium bicarbonate did not always correspond to a greater reduction of OTA as similar trends were observed during the extrusion of rice and oats [21]. During the extrusion of oat flakes, the addition of sodium bicarbonate at $0.5 \%$ and $1.0 \%$ resulted in $57 \%$ and $65 \%$ reduction, respectively, compared to $41 \%$ reduction with no added sodium bicarbonate. In contrast, during the extrusion of rice flour, a lesser reduction of OTA was observed with higher amounts of added sodium bicarbonate, i.e., $75-80 \%$ with $0.5 \%$ and $72-77 \%$ reduction with $1.0 \%$ sodium bicarbonate, in comparison with $78-82 \%$ reduction of OTA without sodium bicarbonate [21]. Meanwhile, a previous study by Lee, Gu, Ganjyal, and Ryu [19] showed a dose-dependent reduction of OTA during DSI processing of oat-based infant cereals. At $121^{\circ} \mathrm{C}$ of DSI, the reduction of OTA was increased from $27.9 \%$ (no additive control) to $44.3 \%$ and $51.4 \%$ with $0.5 \%$ and $1.0 \%$ sodium bicarbonate, respectively, while the same processing at lower temperature of $85^{\circ} \mathrm{C}$ also resulted in similar reductions, i.e., from $19.8 \%$ (no additive control) to $36.1 \%$ and $43.4 \%$ with $0.5 \%$ and $1.0 \%$ sodium bicarbonate, respectively [19]. 
Components or ingredients in the food matrix including sugars may undergo various reactions during processing to result in color changes and production of volatile compounds. Thermal processing of sugars or carbohydrates may also cause alterations in $\mathrm{pH}$ to yield organic acids, such as lactic acid and formic acid [37-40]. With its higher carbohydrate content, rice can produce more organic acids than oats that may positively contribute to the stability of OTA, i.e., acidic conditions. Dahal, Lee, Gu, and Ryu [17] demonstrated previously that OTA is more stable under acidic conditions during thermal processing. Trenk, Butz and Chu [34] also showed lesser OTA reduction in the presence of acetic acid during autoclaving of rice and oatmeal. When high-pressure steaming, such as retorting, was applied to reduce OTA levels with fructose alone or a combination of fructose and sodium bicarbonate [24], the reduction trends by adding additives were different trends with low-pressure steaming, such as indirect steaming used in this study. According to [24], the greater OTA reduction in retorted oat-based porridges was observed by adding fructose (no additives $17.2 \%, 0.5 \%$ fructose $40.8 \%, 5 \%$ fructose $35.5 \%$, respectively), while the decreased OTA reduction in retorted rice-based porridges was observed by increasing amount of fructose (no additives $53.8 \%, 0.5 \%$ fructose $38.7 \%, 5 \%$ fructose $18.2 \%$, respectively). Such observation may be corroborated with a similar extent of OTA reduction between the two groups of fructose alone $(0.5 \%)$ vs. the combination of fructose and sodium bicarbonate $(0.5 \%+0.5 \%)$ suggesting that the mechanisms of the two additives are not in common. Lee, Lee, and Ryu [24] also reported that the reduction of OTA in retorted oat- and rice-based porridges was similar values with $0.5 \%$ fructose treatment when combined with $0.5 \%$ sodium bicarbonate and $0.5 \%$ fructose was added during the retorting process. This is the first study reporting OTA reduction during the manufacturing of common porridge products with added fructose and sodium bicarbonate. These data confirmed that the food matrix can affect the OTA reduction while added fructose or sodium bicarbonate can facilitate the reduction of OTA possibly by changing its $\mathrm{pH}$ conditions. Nonetheless, the decreased OTA concentration determined by HPLC in this study may not correspond to reduced toxicity as varying or unknown degradation products can be formed during the process. Therefore, further research is required to prove the loss of toxicity and to elucidate the mechanism of reaction between OTA and the additives during thermal processes including indirect steaming.

\section{Conclusions}

Simulated indirect steam processing of porridges resulted in significant reductions of OTA, i.e., $59.4 \%$ in rice porridge and $13.6 \%$ in oat porridge. The addition of sodium bicarbonate significantly influenced the reduction of OTA with up to $78.1 \%$ reduction in rice porridge with $0.5 \%$ sodium bicarbonate and $72.6 \%$ reduction in oat porridge with $1 \%$ sodium bicarbonate. Among all levels of added fructose, the highest reduction of OTA resulted from $1 \%$ fructose $(w / w)$ with up to $80.7 \%$ in rice porridge and $69.3 \%$ in oat porridge. Similar to the samples treated with $1 \%$ fructose, adding a combination of $0.5 \%$ fructose and $0.5 \%$ sodium bicarbonate increased the reduction of OTA in rice porridge and oat porridge up to $78.6 \%$ and $67.2 \%$, respectively, in comparison with the porridges without additives. These results indicate that OTA indirect steaming of cereal-based porridge may reduce OTA significantly particularly when sodium bicarbonate and/or fructose are added. For commercial application, additional studies on the residual toxicity need to be performed as the reaction or degradation mechanism of OTA during the indirect steaming process is largely unknown including its degradation products and their toxicity.

\section{Materials and Methods}

\subsection{Chemicals and Materials}

Food-grade oat flour was obtained from the Grain Millers, Inc. (Eugene, OR, USA), and food-grade rice flour was obtained from Bob's Red Mill Natural Foods (Milwaukee, OR, USA). Food-grade fructose and sodium bicarbonate were purchased from Now Foods (Bloomingdale, IL, USA), Church \& Dwight Co. (Arm \& Hammer ${ }^{\circledR}$, Ewing, NJ, 
USA), respectively. HPLC-grade acetic acid (99.5\%), acetonitrile, and methanol as well as phosphate-buffered saline (PBS) tablets were obtained from Fischer Scientific (Pittsburgh, PA, USA). Water (HPLC-grade) was purchased from Macron Fine Chemicals (Center Valley, PA, USA). Commercial OchraTest WB immunoaffinity columns (IAC) were purchased from VICAM (Watertown, MA, USA) for sample cleanup and purification. OTA stock solution $(100 \mathrm{mg} / \mathrm{L})$ was prepared in methanol and further diluted with $50 \%$ methanol (methanol:water $=50: 50 ; v / v$ ) to prepare working standard solutions. All standard solutions were stored in amber vials at $-20^{\circ} \mathrm{C}$.

\subsection{Sample Preparation and Processing}

Rice flour and oat flour were used to prepare porridges and their initial moisture contents were measured to be ca. $12.8 \%$ and $11.6 \%$ (wet weight basis, wb), respectively, by using Model HB43-S Halogen Moisture Analyzer (Mettler Toledo, Greifense, Switzerland). Fifty grams of rice or oat flour were spiked at levels of $20 \mu \mathrm{g} / \mathrm{kg}$ of flour by adding $1 \mathrm{mg} / \mathrm{L}$ OTA solution in methanol and then shaken intermittently for $2 \mathrm{~h}$ for even distribution. Each sample contaminated with OTA $(50 \mathrm{~g})$ was suspended in water $(500 \mathrm{~mL})$ to achieve $10 \%$ of solid basis. Then, sodium bicarbonate $(0.5 \%$ and $1 \%)$, fructose $(0.5 \%, 1 \%, 5 \%$, and $10 \%$ ), and a combination (sodium bicarbonate $0.5 \%$ + fructose $0.5 \% ; w / w$ ), were added to the flour and thoroughly mixed before the cooking process. A stainless steel pot filled with mineral oil was placed on a hot plate stirrer (Hei-Tec, Heidolph, Germany). Mineral oil was used as a heating medium and stirred with a magnetic bar to facilitate uniform distribution of the heat at $225 \mathrm{rpm}$. Then, another stainless steel pot for sample heating treatment was installed in the mineral oil chamber. Prepared rice- or oat-porridge samples were transferred into the pot and heated to $80-85{ }^{\circ} \mathrm{C}$ of center temperature then kept the temperature for $10 \mathrm{~min}$ for gelatinization. After the indirect steaming process, the samples were transferred onto stainless steel trays and then dried in an oven at $50{ }^{\circ} \mathrm{C}$ overnight. Dried samples were ground and then stored in plastic zipper bags at $-20^{\circ} \mathrm{C}$ until analyzed. OTA non-contaminated samples (or blanks) were used to compare with the normal operation of indirect steaming process in relation to the loss of OTA. We also confirmed that drying at $50{ }^{\circ} \mathrm{C}$ overnight did not change OTA levels in samples.

\subsection{Analyses of Color and OTA}

A spectrophotometer (Model CM-5, Konica Minolta Sensing Americas Inc., NJ, USA) was used to measure the color of ground samples according to the method used previously [24].

OTA concentrations in porridge samples were analyzed as described by Lee, Lee, and Ryu [24] with some modifications. In brief, a $5 \mathrm{~g}$ ground sample was extracted with $20 \mathrm{~mL}$ of $80 \%$ acetonitrile (acetonitrile:water $=80: 20, v / v$ ) for $30 \mathrm{~min}$ on a wrist action shaker (Burrell Scientific, Pittsburgh, PA, USA) followed by filtration (Whatman No. 1 filter paper). The filtrate was diluted five times with PBS and filtered again (Whatman No 1). For the sample cleanup, diluted extract $(10 \mathrm{~mL})$ was loaded and passed through an IAC column at a flow rate of about $2 \mathrm{~mL} / \mathrm{min}$, and the column was washed with PBS and water in sequence $(10 \mathrm{~mL}$ each). OTA was then eluted with methanol ( $3 \mathrm{~mL}$ total at about $2 \mathrm{~mL} / \mathrm{min}$ ). The eluate collected in an amber vial was evaporated to dryness under a gentle stream of nitrogen at $50{ }^{\circ} \mathrm{C}$ using an aluminum heating block. The residue was reconstituted in $50 \%$ methanol $(500 \mu \mathrm{L}$, methanol:water $=50: 50 ; v / v)$. Finally, $10 \mu \mathrm{L}$ of the purified extract was injected into HPLC consisted with a vacuum degasser, quaternary pump, autosampler, and fluorescence detector (Agilent 1260 Infinity system, Palo Alto, CA, USA). The chromatographic analysis was performed with a C18 column (Hypersil GOLD, $3 \times 100 \mathrm{~mm}$, particle size $1.9 \mu \mathrm{m}$, Thermo Scientific, Hudson, NH, USA) at room temperature under isocratic elution of a solvent mixture, i.e., $50 \%$ acetonitrile with $0.5 \%$ acetic acid, at a flow rate of $0.4 \mathrm{~mL} / \mathrm{min}$. OTA was detected at the wavelengths of $334 \mathrm{~nm}$ and $460 \mathrm{~nm}$ excitation and emission, respectively. For recovery, OTA was added to rice 
and oat flours at concentrations of 2,10, and $20 \mu \mathrm{g} / \mathrm{kg}$ and then analyzed by following the same procedure described above.

\subsection{Statistical Analysis}

All experiments were replicated three times, and the Statistical Package for Social Sciences version 18.0 (SPSS Inc., Chicago, IL, USA) was used to analyze the data obtained from the experiments. The statistical differences among the treatments were determined by the one-way analysis of variance (ANOVA) with Tukey's multiple range tests in addition to independent t-test $(p<0.05)$. All data are reported as means \pm standard deviation (SD).

Author Contributions: Conceptualization, H.J.L.; methodology, H.J.L.; investigation, S.L. and K.G.; writing—original draft preparation, H.J.L.; writing-review and editing, H.J.L. and D.R.; visualization, H.J.L.; supervision, H.J.L. and D.R.; project administration, H.J.L. and D.R.; funding acquisition, H.J.L. and D.R. All authors have read and agreed to the published version of the manuscript.

Funding: This project was supported by an Agriculture and Food Research Initiative Competitive Grant, Agreement No. 2016-67017-24418, from the USDA National Institute of Food and Agriculture. This research was also partially supported by the International Youth Exchange Foundation of the Henan Academy of Agricultural Science (HAAS) fund.

Institutional Review Board Statement: Not applicable.

Informed Consent Statement: Not applicable.

Data Availability Statement: The data presented in this study are available in article here.

Conflicts of Interest: The authors declare no conflict of interest.

\section{References}

1. Braaten, J.; Wood, P.; Scott, F.; Wolynetz, M.; Lowe, M.; Bradley-White, P.; Collins, M. Oat $\beta$-glucan reduces blood cholesterol concentration in hypercholesterolemic subjects. Eur. J. Clin. Nutr. 1994, 48, 465-474.

2. Queenan, K.M.; Stewart, M.L.; Smith, K.N.; Thomas, W.; Fulcher, R.G.; Slavin, J.L. Concentrated oat $\beta$-glucan, a fermentable fiber, lowers serum cholesterol in hypercholesterolemic adults in a randomized controlled trial. Nutr. J. 2007, 6, 6. [CrossRef]

3. Ramakers, J.D.; Volman, J.J.; Biörklund, M.; Önning, G.; Mensink, R.P.; Plat, J. Fecal water from ileostomic patients consuming oat $\beta$-glucan enhances immune responses in enterocytes. Mol. Nutr. Food Res. 2007, 51, 211-220. [CrossRef]

4. Cappozzo, J.; Jackson, L.; Lee, H.J.; Zhou, W.; Al-Taher, F.; Zweigenbaum, J.; Ryu, D. Occurrence of ochratoxin A in infant foods in the United States. J. Food Prot. 2017, 80, 251-256. [CrossRef]

5. Nguyen, K.T.N.; Ryu, D. Concentration of ochratoxin A in breakfast cereals and snacks consumed in the United States. Food Control 2014, 40, 140-144. [CrossRef]

6. Lee, H.J.; Ryu, D. Significance of ochratoxin A in breakfast cereals from the United States. J. Agric. Food Chem. 2015, 63, 9404-9409. [CrossRef]

7. Roscoe, V.; Lombaert, G.; Huzel, V.; Neumann, G.; Melietio, J.; Kitchen, D.; Kotello, S.; Krakalovich, T.; Trelka, R.; Scott, P. Mycotoxins in breakfast cereals from the Canadian retail market: A 3-year survey. Food Addit. Contam. 2008, 25, 347-355. [CrossRef] [PubMed]

8. Rafai, P.; Bata, R.; Jakab, L.; Vanyi, A. Evaluation of mycotoxin-contaminated cereals for their use in animal feeds in Hungary. Food Addit. Contam. 2000, 17, 799-808. [CrossRef] [PubMed]

9. IARC. Some naturally occurring substances: Food items and constituents, heterocyclic aromatic amines and mycotoxins. In IARC Monographs on the Evaluation of the Carcinogenic Risk of Chemicals to Humans; IARC: Lyon, France, 1993.

10. NTP. Toxicology and carcinogenesis studies of ochratoxin A (CAS No. 303-47-9) in F344/N Rats (Gavage studies). Natl. Toxicol. Program Tech. Rep. Ser. 1989, 358, 1-146.

11. Lea, T.; Steien, K.; Størmer, F.C. Mechanism of ochratoxin A-induced immunosuppression. Mycopathologia 1989, 107, 153-159. [CrossRef]

12. Mayura, K.; Parker, R.; Berndt, W.; Phillips, T. Ochratoxin A-induced teratogenesis in rats: Partial protection by phenylalanine. Appl. Environ. Microbiol. 1984, 48, 1186-1188. [CrossRef]

13. Kuruc, J.; Hegstad, J.; Lee, H.J.; Simons, K.; Ryu, D.; Wolf-Hall, C. Infestation and quantification of ochratoxigenic fungi in barley and wheat naturally contaminated with ochratoxin A. J. Food Prot. 2015, 78, 1350-1356. [CrossRef]

14. Ozbey, F.; Kabak, B. Natural co-occurrence of aflatoxins and ochratoxin A in spices. Food Control 2012, 28, 354-361. [CrossRef]

15. Romani, S.; Sacchetti, G.; Chaves López, C.; Pinnavaia, G.G.; Dalla Rosa, M. Screening on the occurrence of ochratoxin A in green coffee beans of different origins and types. J. Agric. Food Chem. 2000, 48, 3616-3619. [CrossRef]

16. Pardo, E.; Marin, S.; Ramos, A.; Sanchis, V. Ecophysiology of ochratoxigenic Aspergillus ochraceus and Penicillium verrucosum isolates. Predictive models for fungal spoilage prevention-a review. Food Addit. Contam. 2006, 23, 398-410. [CrossRef] 
17. Dahal, S.; Lee, H.; Gu, K.; Ryu, D. Heat stability of ochratoxin A in an aqueous buffered model system. J. Food Prot. 2016, 79, 1748-1752. [CrossRef]

18. Lee, H.J.; Dahal, S.; Perez, E.G.; Kowalski, R.J.; Ganjyal, G.M.; Ryu, D. Reduction of ochratoxin A in oat flakes by twin-screw extrusion processing. J. Food Prot. 2017, 80, 1628-1634. [CrossRef]

19. Lee, H.J.; Gu, B.J.; Ganjyal, G.; Ryu, D. Reduction of ochratoxin A in direct steam injected oat-based infant cereals with baking soda. Food Control 2019, 96, 441-444. [CrossRef]

20. Lee, H.J.; Kim, S.; Suh, H.J.; Ryu, D. Effects of explosive puffing process on the reduction of ochratoxin A in rice and oats. Food Control 2019, 95, 334-338. [CrossRef]

21. Ryu, D.; Kowalski, R.J.; Ganjyal, G.; Lee, H.J. Reduction of ochratoxin A in oats and rice by twin-screw extrusion processing with baking soda. Food Control 2019, 105, 21-28. [CrossRef]

22. Palumbo, J.D.; O'keefee, T.L.; Ho, Y.S.; Santillan, C.J. Occurrence of ochratoxin A contamination and detection of ochratoxigenic Aspergillus species in retail samples of dried fruits and nuts. J. Food Prot. 2015, 78, 836-842. [CrossRef]

23. Van der Stegen, G.H.; Essens, P.J.; Van der Lijn, J. Effect of roasting conditions on reduction of ochratoxin A in coffee. J. Agric. Food Chem. 2001, 49, 4713-4715. [CrossRef]

24. Lee, H.J.; Lee, C.; Ryu, D. Effects of baking soda and fructose in reduction of ochratoxin A in rice and oat porridge during retorting process. Food Control 2020, 107325. [CrossRef]

25. Katofsky, R.E. The Production of Fluid Fuels from Biomass; Princeton University: Princeton, NJ, USA, 1993.

26. Pathare, P.B.; Opara, U.L.; Al-Said, F.A.J. Colour measurement and analysis in fresh and processed foods: A review. Food Bioprocess Technol. 2013, 6, 36-60. [CrossRef]

27. Al-Taher, F.; Cappozzo, J.; Zweigenbaum, J.; Lee, H.J.; Jackson, L.; Ryu, D. Detection and quantitation of mycotoxins in infant cereals in the US market by LC-MS/MS using a stable isotope dilution assay. Food Control 2017, 72, 27-35. [CrossRef]

28. Abrunhosa, L.; Paterson, R.R.; Venâncio, A. Biodegradation of ochratoxin A for food and feed decontamination. Toxins 2010, 2, 1078-1099. [CrossRef] [PubMed]

29. Castegnaro, M.; Tozlovanu, M.; Wild, C.; Molinié, A.; Sylla, A.; Pfohl-Leszkowicz, A. Advantages and drawbacks of immunoaffinity columns in analysis of mycotoxins in food. Mol. Nutr. Food Res. 2006, 50, 480-487. [CrossRef] [PubMed]

30. FDA. CFR-Code of Federal Regulations Title 21. 2017. Available online: www.accessdata.fda.gov/scripts/cdrh/cfdocs/cfcfr/ CFRSearch.cfm?fr=184.1736 (accessed on 1 February 2021).

31. Voss, K.A.; Bullerman, L.B.; Bianchini, A.; Hanna, M.A.; Ryu, D. Reduced toxicity of fumonisin $B_{1}$ in corn grits by single-screw extrusion. J. Food Prot. 2008, 71, 2036-2041. [CrossRef]

32. Jackson, L.S.; Jablonski, J.; Bullerman, L.B.; Bianchini, A.; Hanna, M.A.; Voss, K.A.; Hollub, A.D.; Ryu, D. Reduction of fumonisin $\mathrm{B}_{1}$ in corn grits by twin-screw extrusion. J. Food Sci. 2011, 76, T150-T155. [CrossRef] [PubMed]

33. Gu, K.; Ryu, D.; Lee, H.J. Ochratoxin A and its reaction products affected by sugars during heat processing. Food Chem. 2021, 348, 129038. [CrossRef]

34. Trenk, H.L.; Butz, M.E.; Chu, F.S. Production of ochratoxins in different cereal products by Aspergillus ochraceus. Appl. Environ. Microbiol. 1971, 21, 1032-1035. [CrossRef]

35. Berk, Z. Chapter 1-Physical Properties of Food Materials; Academic Press: Cambridge, MA, USA, 2018.

36. USDA. FoodData Central. Available online: https:// fdc.nal.usda.gov/ (accessed on 1 February 2021).

37. Woo, K.S.; Kim, H.Y.; Hwang, I.G.; Lee, S.H.; Jeong, H.S. Characteristics of the thermal degradation of glucose and maltose solutions. Prev. Nutr. Food Sci. 2015, 20, 102. [CrossRef] [PubMed]

38. Salak Asghari, F.; Yoshida, H. Acid-catalyzed production of 5-hydroxymethyl furfural from D-fructose in subcritical water. Ind. Eng. Chem. Res. 2006, 45, 2163-2173. [CrossRef]

39. Fagerson, I.S. Thermal degradation of carbohydrates; a review. J. Agric. Food Chem. 1969, 17, 747-750. [CrossRef]

40. Khajavi, S.H.; Kimura, Y.; Oomori, T.; Matsuno, R.; Adachi, S. Kinetics on sucrose decomposition in subcritical water. LWT-Food Sci. Technol. 2005, 38, 297-302. [CrossRef] 